\title{
Una propuesta para la formación pedagógica del profesor universitario: un enfoque formativo previo
}

\author{
A proposal for the pedagogical training of university \\ professor: A previous formative approach
}

Juan P. Vázquez Pérez ${ }^{1}$

\begin{abstract}
Resumen: En este artículo se presenta una propuesta inédita para la formación pedagógica del profesorado universitario, resultado de un análisis de contenido. En esta se resaltan, desde un punto de vista particular, diversos elementos de los procesos de planificación, enseñanza, assessment ${ }^{2}$ y evaluación del aprendizaje, poniéndose énfasis en la responsabilidad que requiere llevarlos a cabo. Asimismo, se pone énfasis en el rol de las instituciones universitarias, respecto a la formación pedagógica de su profesorado, como garantía para ofrecer una enseñanza de calidad, a partir de la premisa de que esta es tarea de todos en la Universidad.
\end{abstract}

Palabras clave: práctica pedagógica, formación inicial, enseñanza superior, calidad de la enseñanza, profesión docente.

\footnotetext{
${ }^{1}$ Doctor en Pedagogía. Docente de la Universidad de Puerto Rico, Recinto de Río Piedras. Corozal, Puerto Rico. E-mail: juan.vazquez24@upr.edu.

2 "Proceso de recopilación de información acerca del estudiante para ayudar en la decisión que se toma del progreso y desarrollo del estudiante" (Joint Committee on Standards for Educational Evaluation, 2003, p. 225). Dicha información incluye, pero no se limita, a las siguientes: observaciones, escritos, exámenes o pruebas en clase, pruebas estandarizadas, actividades de assessment (e.g., individuales, en pareja o grupales), interrogatorios orales, entrevistas, presentaciones orales, portafolios, proyectos o creaciones, productos del assessment de la ejecución, entre otras. Verdejo y Medina (2009) indicaron que el concepto assessment, tal y como se plantea en la definición anterior, carece de una traducción literal al castellano, es decir, de una palabra que encierre su significado en el contexto educativo, por lo que recomendaron que se utilice en el idioma inglés.
}

Diálagas Pedagágicas. ISSN en línea: 2524-9274

Año XVI, No 32, octubre 2018-marzo 2019. Pág. 1-29

DOI: http://dx.doi.org/10.22529/dp.2018.16(32)01 / Recibido: 3-03-2018 / Aprobado: 15-06-2018

Artículo publicado bajo Licencia Creative Commons Atribución-NoComercial-SinDerivar. (c) Universidad Católica de Córdoba. 
Abstract: This article presents a new proposal for the pedagogical training of the university faculty staff that is the result of a content analysis. The article highlights, from a particular point of view, various elements of the processes of planning, teaching, assessment, and evaluation of learning, with emphasis on the responsibility that requires carrying them out. In the same way, emphasis is placed on the role of university institutions, regarding the pedagogical training of professors, as a guarantee to deliver a quality education, establishing that it is task for all members in the University.

Key words: teaching practice, initial training, higher education, teaching quality, teaching profession.

\section{Trasfondo histórico-conceptual}

Durante sus varios siglos de historia, la Universidad ha estado transformándose continuamente, aún más en los últimos siglos, observándose dificultades en torno a cambios estructurales, de contenidos y de dinámicas de funcionamiento, para adaptarse a los nuevos desafíos que la sociedad impone (Monereo, 2013; Perales, Jornet \& González, 2014; Rodríguez, 2008; Salas, 2000; Zabalza, 2007). En estas últimas décadas, uno de los mayores cambios que se ha dado ha sido la restructuración del proceso de enseñanza a raíz de la nueva concepción del aprendizaje, cuestión que ha tenido sus efectos en las metodologías para enseñar (Barberà, 2008; Baute \& Iglesias, 2014; Concepción, Fernández, \& González, 2014; de Miguel, 2006; López Camps, 2005; Martínez, 2010; Pabón et al., 2009; Pimienta, 2011; Stes \& Van Petegem, 2015; Villarroel, 1995). En esta se pone como centro de la enseñanza al estudiante y su aprendizaje, lo que ha implicado nuevas responsabilidades en el rol del profesor (Aramburuzabala, Martínez-Garrido, \& García-Peinado, 2013; Barberà, 2008; Cano \& Revuelta, 1999; Concepción et al., 2014; de Miguel, 2006; López Camps, 2005; López Noguero, 2005; Martínez, 2010; Ordóñez, 2004; Pabón et al., 2009; Villarroel, 1995). En efecto, la figura del profesor ha ido evolucionando (Asensio, 2000; Barberà, 2008; Bolívar \& Caballero, 2008; Lucarelli, 2008; Mas \& Ruiz, 2007; Moreno, 2009; Pabón et al., 2009; Sánchez \& Mayor, 2006; Villarroel, 1995), pasando de ser el centro (i.e., único difusor o transmisor de un conocimiento específico) a un facilitador y guía del aprendizaje. Pues, "la enseñanza no significa ya impartir todo el programa de la asignatura, sino mejorar el aprendizaje" (Stes \& Van Petegem, 2015, p. 16). Por consiguiente, se espera que el profesor proporcione los conocimientos necesarios, a través de experiencias variadas, para que el estudiante vaya construyendo su conocimiento en torno a un tema específico (de Miguel, 2003; Knapper, 2009; Mas \& Ruiz, 2007; Mauri, Coll, \& Onrubia, 2007; Mérida, 2006; Ordóñez, 2004; Pabón et al., 2009; Reyes, 2000; Villarroel, 1995). Al mismo tiempo, debe utilizar diferentes recursos para que el estudiante amplíe el conocimiento que se le facilita; de este modo se dejan atrás los momentos presenciales como único medio para que se dé la comunicación (Barberà, 2008; Bolívar \& Caballero, 2008). Sin embargo, su función en 
torno a la investigación no deberá descuidarse, pues facilita el manteniendo y actualización constante en su área de especialidad; aunque esta no deberá opacar o descuidar la actividad docente.

Como secuela, la formación pedagógica del profesorado es un tema que ha tomado un auge en las pasadas décadas, pero en especial en los últimos años (Álvarez et al., 2012; Baute \& Iglesias, 2014; de la Cruz, 2000; de Miguel, 2003; Fernández, 2008; Monereo, 2013; Noguera, 2001; Palomero, 2003; Perales et. al., 2014; Zabalza, 2005, 2007, 2009), lo cual ha sido uno de los adelantos que ha contribuido al mejoramiento de la calidad de la enseñanza (Fernández, 2008). Así, la Professional and Organizational Development Network in Higher Education (2016), en su página electrónica, puso énfasis en que el desarrollo profesional de la facultad debe incluir esfuerzos para fortalecer tres roles del docente: (a) instructor individual o un miembro de facultad; (b) instructor académico-profesional; y (c) instructor como persona. Esta formación en torno a estos roles se observa necesaria a partir de la respuesta que se está dando a los retos que imponen la "sociedad de conocimiento" y las concepciones acerca del aprendizaje a lo largo de la vida (Cano \& Revuelta, 1999; de Miguel, 2003; Galán, 2007; Lucarelli, 2008; Mas \& Ruiz, 2007; Mauri et al., 2007; Pabón et al., 2009; Salas, 2000) que, a su vez, tienen repercusiones en el proceso de enseñanza. En efecto, en la Universidad actual se necesitan profesores que sean capaces de trabajar en un contexto cambiante y diverso, en el que se enfrentarán con distintas exigencias que inciden en la figura del profesor. Así pues, deben ser capaces de manejar la diversidad en su aula de clases para así, dirigir su enseñanza hacia el aprendizaje de los estudiantes (Karjalainen, Alha, \& Jutila, 2009), y facilitar a estos los recursos necesarios para que dominen las competencias de su perfil profesional.

A pesar de la poca participación de los profesores en actividades de formación, como manifestó Rodríguez (2003), a través de los años se ha ido despertando un interés en el mejoramiento de la práctica docente (Aramburuzabala et al., 2013; de la Cruz, 2000; Fernández, 2008; Leonetti et al., 2010; Muñoz, 2004; Palomero, 2003; Prieto, 2004). El profesor está comenzando a preocuparse por desempeñar bien su rol atendiendo asuntos específicos acerca del proceso de enseñanza. No obstante, la carencia de normativas respecto a la formación previa, en muchos contextos universitarios, hace que esta obtenga un carácter voluntario (Caballero, 2013; de la Cruz, 2000; Sánchez \& Mayor, 2006; Fernández, 2008; Palomero, 2003), por lo que gran parte del profesorado se queda sin formación. Respecto a este asunto, Postareff y Nevgi (2015), a raíz de sus investigaciones, identificaron cinco tipos de profesores: (a) profesores que tienen un pausado desarrollo y cambios en sus concepciones y prácticas; (b) profesores que presentan cambios inesperados en sus concepciones; (c) profesores que tienen menos cambios conceptuales, pero más cambios en sus prácticas de enseñanza; (d) profesores que demuestran resistencia al principio, pero que eventualmente experimentan cambios, especialmente en sus concepciones; y (e) profesores que se aferran a la resistencia hacia el cambio.

Por tanto, se observa de forma evidente que todavía hoy los profesores frecuentan actividades de formación solo en sus respectivas áreas de especialidad 
(Biscarri, Filella, \& Jové, 2006; García-Valcárcel, 2001; Noguera, 2001; Urosa, 2004; Zabalza, 2005, 2009), dejando rezagada la formación en el área pedagógica. Sin embargo, cuando se trabaja como profesor, aún más en un contexto universitario, deben mantenerse actualizados los conocimientos en ambas áreas académicas (Álvarez et al., 2012; Aramburuzabala et al., 2013; Caballero, 2013; Cáceres et al., 2003; de la Cruz, 2000; de Miguel, 2003; Fernández, 2008; Mérida, 2006; Sánchez \& Mayor, 2006; Ruiz, 2010; Yot \& Mayor, 2012; Zabalza, 2007), porque tan importante es conocer y actualizar los contenidos de la especialidad como la pedagogía que contribuye a la enseñanza óptima de tales contenidos. De esta forma, pueden desarrollarse diferentes ámbitos: el profesional, el pedagógico y el personal, tal y como lo propusieron la Professional and Organizational Development Network in Higher Education (2016) y Zabalza (2005).

\section{Planteamiento del problema}

A pesar de que lo que se conoce hoy como desarrollo profesional tiene sus bases en el año 1810, cuando la Universidad de Harvard comenzó a conceder licencias sabáticas a los profesores para tal fin (Sorcinelli, Austin, Eddy, \& Beach, 2006), hoy sigue observándose la preocupación en muchos profesores de no saber enfrentarse a las nuevas exigencias didácticas y evaluativas, lo que les imposibilita adaptarse (Prieto, 2004). Esto puede apoyarse en la realidad de que en las universidades se cuenta con profesionales, especialistas en áreas específicas del saber, pero que no necesariamente tienen un conocimiento pedagógico para impartir la enseñanza. En ocasiones puede llegarse a afirmar que este no garantiza el aprendizaje de los estudiantes, pero, al menos lo posibilita (de la Herrán, 2003). Es decir, que el conocimiento pedagógico facilita las bases para que se estructure y organice el proceso de enseñanza de tal manera que el estudiante pueda construir su conocimiento y hacerse partícipe de su aprendizaje. No obstante, todo esto también depende del conocimiento previo que posea el estudiante y del trabajo que realice. Aun así, visto desde el punto de vista del profesor, debe hacerse todo lo posible para garantizar que el proceso de enseñanza sea eficaz. Pues, el profesor es el primer responsable en el proceso de enseñanza universitario y es en quien las instituciones universitarias ponen su confianza para, a su vez, promover la calidad docente (Aquino, Magaña, \& Rosas, 2013; Aramburuzabala et al., 2013; de Miguel, 2003; Galán, 2007; Marcelo \& Vaillant, 2009; Sánchez \& Mayor, 2006).

En relación con esta calidad docente se encuentra la evaluación del aprendizaje. Puede afirmarse que esta debe realizarse de la mejor manera posible, para que se evidencien adecuadamente los resultados de la enseñanza, lo cual hace indudable su crucial e importante relación con la calidad de la enseñanza (Álvarez, 2008; Biggs, 2008; Bolívar \& Caballero, 2008; Cebrián, 2008; de la Calle, 2004; Ibarra \& Rodríguez, 2010; McMillan, 2014; Moreno, 2009; Mueller, 2005; Muñiz \& Fonseca-Pedrero, 2008; Trillo, 2005; Vera Vélez, 2002; Verdejo \& Medina, 2009; Zabalza, 2009). En efecto, tener el conocimiento necesario acerca de la evaluación del aprendizaje podría facilitar que los profesores no repitan los métodos para evaluar que utilizaban los profesores que formaron parte de su preparación aca- 
démica (López Noguero, 2005; Monereo, 2013; Urosa, 2004), los cuales no necesariamente demostraban dominio de la evaluación del aprendizaje y los principios éticos ${ }^{3}$ que este proceso implica. Así pues, se pone énfasis en la necesidad de conocimiento en torno a la evaluación del aprendizaje y al mejoramiento de su práctica (Cebrián, 2008; de la Calle, 2004; Lucarelli, 2008; Moreno, 2009; Muñiz \& Fonseca-Pedrero, 2008; Sánchez \& Mayor, 2006). En un proceso de evaluación adecuado se utilizan diversas técnicas para tratar de evidenciar el dominio de contenidos específicos (i.e., un proceso de assessment) (Álvarez, 2008; Mueller, 2005) y, a su vez, tratar de dirigir el pensamiento de los estudiantes hacia niveles altos en los dominios cognoscitivos (McMillan, 2014; Vera Vélez, 2002; Verdejo \& Medina, 2009); lo que finalmente conduce a emitir un juicio acerca del aprendizaje del estudiante.

En consecuencia, las exigencias que han advenido al contexto educativo universitario, ya sean como producto de las nuevas concepciones del proceso de enseñanza centrado en el aprendizaje del estudiante o por las normativas de educación superior, principalmente se relacionan con las demandas de la sociedad acerca de la calidad en la enseñanza. Estas se observan más en los aspectos que se relacionan con el uso de nuevas metodologías para enseñar, con el rol que el profesor debe ejercer, con la evaluación continua y con el seguimiento individualizado del progreso de los estudiantes (Caballero, 2013; Gairín, 2011; Monedero, 2007; Perales et. al., 2014; Stankeviciene, 2007; Vizcarro, 2009). En relación con esto, Aciego, Martín y García (2003), Concepción, Fernández y González (2014) y López, González y de León (2014) encontraron a través de sus estudios que los profesores necesitan formación en torno a la metodología didáctica que enfatice en los procesos de planificación, ejecución y evaluación, propiciando, a su vez, estrategias didácticas para contenidos específicos. También, requieren formación acerca de la utilización de los recursos tecnológicos y de la aplicación de estrategias para la motivación y el desarrollo cognoscitivo. Sin embargo, Sales (2006) determinó

\footnotetext{
${ }^{3}$ De acuerdo con Verdejo \& Medina (2009), la evaluación del aprendizaje, como área profesional, requiere la utilización de diferentes técnicas que, al utilizarse en otras disciplinas académicas, demandan de una serie de principios éticos que son relativos a su utilización y efecto con los seres humanos. Estas autoras indican que, por relevancia de estos asuntos, se ha legislado en torno a su aplicabilidad y para garantizar un proceso ético. Tales principios éticos son los siguientes: la beneficencia implica que las experiencias evaluadoras deben realizarse en beneficio para los estudiantes y su aprendizaje (e.g., evaluar solo en torno temas discutidos en clase). La no maleficencia pone énfasis en la utilización de técnicas que no impliquen un riesgo físico o psicológico, más allá de los que se confrontan en la vida cotidiana (e.g., no igualar o simplificar la complejidad del aprendizaje a la puntuación que se obtenga). La autonomía encierra el conocimiento de antemano de los procesos evaluativos a los que se someterán los estudiantes (e.g., criterios para la evaluación, porcentajes que representarán las diferentes tareas de ejecución). La justicia implica el ofrecimiento, con equidad, de diferentes oportunidades a los estudiantes para demostrar el aprendizaje y la aplicación del mismo (e.g., no demostrar tratos preferenciales, no estigmatizar). La privacidad requiere la utilización adecuada de la información personal, en la que se incluyen los resultados de las evaluaciones, de manera que no se divulgue nada que no sea de dominio público (e.g., publicación de listas de notas, inmersión de estudiantes en tareas propias del profesor). La integridad abarca la rectitud, la honradez y la veracidad en todo lo que concierne el trabajo docente, especialmente en la evaluación del aprendizaje (e.g., demostrar consistencia, respeto y rectitud como docente). Todos estos principios éticos deben facilitar el funcionamiento adecuado de la actividad docente poniendo énfasis en el estudiante y su aprendizaje.
} 
que la formación pedagógica debía abarcar asuntos en los que se ponga énfasis en una enseñanza que permita la interpretación, comprensión y reflexión de conceptos que se relacionen con contenidos específicos de las asignaturas, dejando a un lado la enseñanza unidireccional (i.e., transmisión de conocimiento de manera pasiva). Así pues, todo esto refleja que hay profesores interesados en mejorar su práctica educativa (Álvarez et al., 2012; de la Cruz, 2000; Fernández, 2008; Leonetti et al., 2010; Muñoz, 2004; Palomero, 2003; Prieto, 2004). Pues, en muchas ocasiones se "abandona la docencia a la suerte y habilidad del principiante" (Caballero, 2013, p. 393). No obstante, cabe resaltar que "los profesores a veces pueden rechazar las nuevas teorías y prácticas como innecesaria y su destreza como académicos sigue siendo indiscutible" (Postareff \& Nevgi, 2015, p. 47).

\section{Método}

En este estudio se utilizó una metodología cualitativa con un diseño de análisis de contenido. De acuerdo con Creswell (2012), la metodología cualitativa debe utilizarse cuando se requiere una exploración y descripción de un fenómeno de interés. También, por medio de esta metodología se busca obtener información con el propósito de entender un fenómeno de interés (Taylor \& Bogdan, 1988). Por su parte, Hernández, Fernández-Collado y Baptista (2014) indicaron que en una investigación con una metodología de enfoque cualitativo se recopilan datos sin medición numérica, con el fin de descubrir o perfeccionar preguntas de investigación en el proceso de interpretación. Así pues, McMillan (2012) puso énfasis en que en la investigación cualitativa se busca examinar a profundidad la cualidad de las relaciones, procesos, actividades, situaciones o contenidos específicos.

Entre los diseños cualitativos, se eligió el diseño de análisis de contenido. Este diseño es un modo de investigación que permite hacer replicable y válidas las inferencias a partir de textos (Krippendorff, 2004). Respecto a esto, este autor añadió que el análisis de contenido permite descubrir o establecer nuevas ideas, aumenta el entendimiento de un fenómeno de interés o informa acerca de acciones prácticas. Por su parte Altheide, Coyle, DeVriese y Schneider (2008) indicaron que un análisis de contenido permite combinar diferentes pasos investigativos con fin de profundizar acerca de conceptos, datos y cualquier otra información que emerja de lo mismo que se analiza. En efecto, estos autores han resaltado que en este tipo de diseño, el investigador debe introducirse en el área de estudio, lo que requiere tener contacto directo con numerosos documentos que le faciliten realizar una comparación sistemática y constante.

\section{Propósito del estudio}

Este estudio tuvo como propósito proponer un proceso para la estructuración de la formación pedagógica y el desarrollo profesional del futuro profesor universitario, para que este: (a) pueda desarrollarse como docente en el contexto en el que se desempeña; (b) ofrezca una enseñanza de calidad que redunde en la dirección del aprendizaje de los estudiantes; y (c) evidencie su desarrollo profe- 
sional promoviendo la calidad en la enseñanza universitaria. En la documentación del proceso de formación pedagógica se exploraron contenidos, metodologías, estrategias y técnicas que se recomiendan para llevar a cabo la planificación y ejecución del proceso de enseñanza y la evaluación del aprendizaje estudiantil, en el contexto universitario. A su vez, se auscultaron formas para evidenciar la calidad de la enseñanza en las instituciones universitarias, a partir del desarrollo profesional del profesor y la evaluación de su actividad docente. Inicialmente, la propuesta para la formación pedagógica fue para el contexto universitario español, pero puede extrapolarse; pues, el contenido de la formación es aplicable a cualquier contexto universitario.

\section{Preguntas de investigación}

Por ser esta una investigación cualitativa, Creswell (2012) recomendó que se utilice una pregunta central de investigación seguida de preguntas específicas. Estas deben facilitar la recopilación de información acerca de todas las áreas o aspectos que componen la pregunta central de investigación. La pregunta central de este estudio fue:

- ¿Cómo debe planificarse una formación pedagógica que se dirija al desarrollo profesional del profesor universitario capacitándole para llevar a cabo un proceso de enseñanza de calidad?

En consecuencia, a partir de la pregunta central de investigación, se presentan las preguntas específicas, a saber:

- ¿Cómo debe llevarse a cabo la formación pedagógica y el desarrollo profesional del profesor universitario en torno a los siguientes procesos de la enseñanza?

- Planificación.

- Ejecución.

- Assessment y evaluación del aprendizaje.

- ¿Qué aspectos del desempeño del profesor deben auscultarse para evidenciar su desarrollo profesional y, a su vez, promover una enseñanza de calidad?

- ¿De qué manera las instituciones universitarias deben involucrarse en el proceso de formación pedagógica de sus profesores para garantizar la calidad de la enseñanza?

\section{Selección de las fuentes de información: muestra}

La selección de las fuentes de información que formaron parte de esta investigación se hizo de forma intencional a base de criterios. Este tipo de método permite seleccionar fuentes que provean información necesaria y valiosa que, a su vez, ayude a contestar las preguntas de investigación (Creswell, 2012; McMillan, 2012). Cabe destacar, que la intencionalidad a base de criterios facilita la identificación y selección de fuentes con unas características específicas, lo que le otorga mayor profundidad a la información. Para McMillan (2012) la fortaleza de este mé- 
todo es que, a través de las fuentes que se estudien se obtiene información completa, o sea, información específica y detallada acerca del tema bajo estudio. Así, pueden hacerse inferencias más específicas que, de una mejor manera, hagan referencia al fenómeno de interés en el contexto en el que estudie (Altheide, Coyle, DeVriese, \& Schneider, 2008; Corbin \& Strauss, 2008; Krippendorff, 2004; Silverman, 2003).

Como parte de las fuentes para el análisis de contenido, se incluyeron 183 documentos. De los cuales, 30 fueron libros o manuales que se relacionaban con lo que implica la actividad docente y la calidad del proceso de enseñanza universitario, 49 fueron artículos de carácter empírico acerca de asuntos que se relacionan con el área de educación, 94 fueron artículos con carácter informativo o argumentativo acerca de la formación pedagógica del profesorado universitario y 10 fueron documentos legales que se relacionaban con asuntos específicos de la universidad. La identificación y selección de fuentes incluyó documentos, a los que se tuvo acceso, con fecha de publicación desde el 1 enero de 2000 hasta el 31 de julio de 2011. Sin embargo, se incluyeron 17 documentos publicados antes del año 2000, porque en su contenido se hacía referencia a asuntos relevantes a la investigación o porque eran publicaciones de autores clásicos. Cabe resaltar que pudo haber fuentes que se relacionaran con el tema que, por los criterios de selección, por ser inéditas o por el juicio del investigador, no se incluyeron como parte de la investigación. Aun así, las fuentes que se seleccionaron fueron suficientes para trabajar el problema bajo estudio, llegándose al punto de saturación. No obstante, para propósito de este artículo, se incorporó literatura reciente, lo que permite demostrar la continuidad del estudio en torno al tema de interés.

\section{Procedimiento}

El procedimiento que sugirió Krippendorff (2004) para un análisis de contenido se reduce a seis pasos. Estos evidencian la necesidad de que el investigador se dirija desde los textos hacia los hallazgos. Esta secuencia lógica se estructura de la siguiente manera:

1. Delimitar el tema y el contexto de la investigación.

2. Identificar y seleccionar las fuentes.

3. Codificar los textos de acuerdo con los temas que emerjan del contenido.

4. Reducir los datos para hacer síntesis o simplificar la información.

5. Hacer inferencias acerca del fenómeno bajo estudio en referencia al contexto.

6. Redactar la respuesta a las preguntas de investigación y establecer conclusiones.

Para presentar el procedimiento en el contexto de esta investigación, se dividió el proceso en dos fases (a) Recopilación de datos y (b) Análisis de los datos. La primera fase incluye los primeros dos pasos que recomendó Krippendorff y la segunda fase hace referencia a los pasos subsiguientes. La descripción de cada fase se presenta a continuación. 
Recopilación de datos. De acuerdo con Silverman (2003) y Hernández et al. (2014), en la investigación cualitativa la recopilación de datos considera como una fuente valiosa los documentos, los registros y diversos materiales de la misma índole. Así pues, la búsqueda, identificación y selección de fuentes se llevó a cabo siguiéndose las recomendaciones de Silverman, quien indicó que debe delimitarse la selección de fuentes, por tema y por tipo, para realizar un trabajo de análisis más efectivo; lo que, a su vez, guardó estrecha relación con el muestreo por criterios. Finalmente, para revisar la correspondencia de las fuentes con las preguntas de investigación, se estructuró la búsqueda, revisión y selección de las fuentes en referencia a las preguntas. De esta forma, se facilitó, aún más, la selección de la información y, al mismo tiempo, el análisis de esta (Silverman, 2003).

Análisis de los datos. En el contexto de esta investigación, luego de leer los documentos que se consultaron para clasificarlos a partir de los temas generales que en ellos se abordaron, se separó el contenido de los documentos en dos partes (a) información general e (b) información específica. Con la información general se trabajó en la parte teórica, específicamente, haciendo un resumen del estado de la cuestión acerca de la calidad de la enseñanza, desde la perspectiva de los cambios que se han producido en la universidad, de la evolución del rol del profesor y de la necesidad de la formación pedagógica de este. De este resumen, se partió para realizar el análisis de contenido en profundidad, el cual se hizo solo con la información específica de los documentos. Este permitió trabajar con los asuntos correspondientes a la formación pedagógica del profesor universitario, a los aspectos de su desempeño que se relacionaban con la calidad de la enseñanza y al rol de las universidades en torno a la formación pedagógica de su profesorado, en vías de garantizar la calidad de la enseñanza. Cabe resaltar que las decisiones que tomó el investigador para trabajar con las fuentes se justifican a partir de las ideas que plantearon Hernández et al. (2014): "La perspectiva del investigador en el análisis de los datos es interna. El investigador involucra en el análisis sus propios antecedentes y experiencias, así como la relación que tuvo con los participantes [i.e., las fuentes] del estudio" (p. 15).

Para el análisis de contenido en profundidad, se utilizó el diseño de codificación sistemática de Corbin y Strauss (2008) cumpliendo, a su vez, con los pasos que recomendó Krippendorff (2004). Para la codificación sistemática, Corbin y Strauss establecieron tres pasos para que se cumpla con el objetivo principal del análisis de la información: procurar el entendimiento y la claridad necesaria acerca del fenómeno que se estudia. Estos pasos fueron: (a) categorización, que implicó depurar, segmentar e integrar la información que se recopiló en categorías o temas generales; (b) codificación axial, en la que se establecieron relaciones temáticas entre las categorías; y (c) discusión y presentación de los hallazgos, donde se comenzó a responder las preguntas de investigación y determinar conclusiones y recomendaciones). Así pues, se redujo la información, pasando a un análisis más específico y dirigido, donde se comenzó con las inferencias acerca del fenómeno bajo estudio (i.e., el profesor y su desempeño como docente, en relación con la formación pedagógica y la calidad de la enseñanza). Estas inferencias facilitaron el esbozo de los hallazgos de la investigación, lo que permitió visualizar cuáles contenidos podrían seleccionarse para sustentarlos. Respecto a este asunto 
en particular, cabe resaltar que de esta forma se aumentó la credibilidad de los hallazgos, lo cual fue una evidencia para la validez interna de la investigación.

\section{Hallazgos}

Luego de realizar el análisis de la información que se recopiló, se estudiaron, nuevamente, las preguntas de investigación, lo que facilitó establecer una correspondencia entre el contenido de ellas y los hallazgos que resultaron del análisis. Para aumentar la credibilidad de los hallazgos, como parte de la argumentación que se presenta en los diferentes epígrafes, se incorporan citas directas de las fuentes que se analizaron. Esto permite que se sustenten los resultados con las fuentes del análisis y que se argumenten los planteamientos que se exponen. De esta forma, lo que se plantea tiene fundamento, otorgándole lógica y validez. También, esto refleja la utilidad y la aplicabilidad de las fuentes, que en un análisis de contenido son la base para trabajar.

\section{Supuestos para el interesado en ejercer la docencia universitaria}

Todo interesado en ejercer la docencia en el contexto universitario debería contar con unos conocimientos pedagógicos, que le faciliten su desempeño profesional, además de su preparación académica en un área específica. Tal interesado debe, desde un principio, comenzar a verse como profesional de la enseñanza. En relación con esto, Zabalza (2007) afirmó que "en la configuración de la identidad profesional de los docentes universitarios es necesario el paso de ser simple especialista de la materia a ser didacta de la disciplina" (p. 108). Por su parte, de la Cruz (2003) reiteró en que se llega a ser profesor a través de "la disposición, el compromiso y el empeño con que se afronte la actividad docente y la formación pertinente. No hay ejercicio profesional de calidad sin una formación específica y sistemática sobre el oficio correspondiente" (p. 38). Así pues, todo interesado en la docencia deberá entender que ser docente en este contexto implica saber enseñar lo que se le asigne enseñar. De esta forma, puede darse comienzo a la ruptura de estereotipos, mitos o creencias personales y despectivas acerca de la enseñanza universitaria. Si importante es la enseñanza primaria y secundaria, en tanto que preparan a los estudiantes para el mundo universitario, igualmente importante es la enseñanza universitaria porque forma a los futuros profesionales de la sociedad.

De esta forma, el futuro docente universitario deberá visualizarse, más que como un erudito o ser superior en torno al conocimiento, como un facilitador del conocimiento que posee. Es necesario "enmarcar la formación docente en posicionamientos evolutivos, que puedan superar una cultura transmisora y/o aquellos modelos centrados en un entrenamiento técnico" (Reyes \& González, 2007 , p. 152). Por esto, no se trata de demostrar cuánto se sabe exponiendo clases magistrales que solo entienda el profesor, sino que se trata de traducir el conocimiento y facilitarlo a aquellos que van en busca de este. Respecto a esto, Biscarri, Filella y Jové (2006) mencionaron que los profesores "dedican esfuerzos 
en la preparación de la asignatura, sobre todo en la actualización de contenidos, aunque se observa una falta de actitud innovadora, es decir, siguen una metodología tradicional, muy estructurada" (p. 293). A esto se le añade, que al momento de evaluar el aprendizaje utilizan los métodos menos indicados $y$, a su vez, no toman en cuenta los principios éticos de dicho proceso, evidenciándose como un proceso cíclico en el cual, el discípulo repite las mismas acciones de sus maestros sin tener nociones de lo que necesita para ejercer adecuadamente la docencia.

Por tal razón, el interesado en la docencia deberá preocuparse por cambiar todo aquello que le resultó una experiencia negativa en su formación. Es decir, tratar de mejorar las deficiencias que él mismo pudo identificar con poco entendimiento de lo que es saber enseñar, pero que se reflejaban en contraposición de sus ansias por aprender. En efecto, deberá mostrar interés hacia lo que le permita capacitarse para poder desempeñar una actividad docente que responda a las necesidades de los estudiantes, que atienda la diversidad y que dirija el pensamiento hasta alcanzar niveles altos de dominio cognoscitivo. En fin, observarse como el que se dedica a su actividad docente otorgándole la importancia y el mérito necesarios para desempeñarla óptimamente (de la Calle, 2004; Newman, 1996; Rodríguez, 2003), lo que, al mismo tiempo, podría conducir a que se rompa con diversos mitos que fomentan el menosprecio de la docencia, especialmente en el contexto universitario.

En consecuencia, el interesado en ejercer como docente en el contexto universitario deberá reconocer y concienciarse que el rol que desempeñará será uno de suma importancia para el desarrollo de una docencia que garantice la calidad, que es uno de los asuntos prioritarios de la universidad en la actualidad. Además, deberá sensibilizarse en torno a la identidad profesional que asumirá y de la trascendencia que tendrá en la formación estudiantil. Respecto a esta identidad, Zabalza (2005) puso énfasis en que "la historia de las dos identidades, como especialista en un área y como profesor al final para funcionar bien, tiene que convertirse en una sola, porque es lo que ayuda a entender al profesor el trabajo que está haciendo" (p. 102). Así pues, se espera que dicha fusión configure la profesionalidad de un profesor universitario que se dedique principalmente a la docencia.

Siguiendo las palabras que Monedero (2007) utilizó al afirmar que la preparación pedagógica del profesor puede incidir en la eficacia y la satisfacción de la enseñanza, lo que conduce a la calidad de esta, se espera que la propuesta que aquí se presenta motive a diferentes instituciones de educación superior a promover en su profesorado la actualización pedagógica, desde su identidad docente y en torno a la facilitación de un proceso de enseñanza que propicie la eficacia, desde el punto de vista del aprendizaje del estudiante. Sin embargo, según afirmaron Torra et al. (2013), debe tenerse en cuenta que en muchos países esta formación previa no es una realidad, tal y como se observa para otras profesiones. Según estos autores, "es necesario abordar la disfunción que representa el hecho de que el profesorado universitario pueda acceder a la función docente sin tener una formación previa" (p. 302). Así pues, la propuesta que se presenta a continuación, puede extenderse a una formación inicial que forme parte de requisitos de contratación en universidades en las que se desee garantizar la calidad 
de la enseñanza. Esto puede facilitarse por la misma institución universitaria, ofreciéndose como parte del contrato para acceder a la docencia, tal y como se realiza en universidades prestigiosas de Reino Unido, Australia, Noruega, entre otras (Baume \& Baume, 2001; Fernández, 2008; Zabalza, 2005). De esta forma, es la misma universidad quien se preocupa por garantizar que la enseñanza que se imparta en ella sea eficaz, de acuerdo con su misma visión y misión.

\section{Propuesta para una formación en docencia universitaria: contenidos es- pecíficos}

Los contenidos de la formación que se proponen responden a una serie de necesidades que el autor ha ido identificando en la literatura, que todavía hoy sigue profundizándose, para reafirmar la importancia de la formación pedagógica del profesorado universitario y en vías de que se profesionalice la docencia universitaria, otorgándosele la importancia que merece, por su relevancia dentro de la formación académica que se ofrece en la universidad. Así, a través de esta propuesta, se pretende dar a conocer una visión general y diferente acerca del desarrollo de la formación pedagógica del futuro profesor universitario.

El docente universitario actual debe tener un conocimiento pedagógico que le permita ejercer la práctica de la enseñanza y reflexionar acerca de esta, de manera que se propicie el trabajo activo del estudiante tanto dentro como fuera del aula de clases, con el fin de que desarrolle al máximo sus capacidades hasta hacerse autónomo de su aprendizaje. Por esto, el profesor debe estar preparado para ofrecer los recursos necesarios que favorezcan ese desarrollo en los estudiantes y les permita acceder a las experiencias necesarias que les ayuden a lograrlo. Así pues, el estudiante podrá demostrar que conoce su área de especialidad al mismo tiempo que sabe estar, compartir y trabajar en equipo y llevar a cabo las tareas pertinentes a su profesión. Respecto a estos asuntos, Rué (2009) indicó que

las intervenciones docentes que pretendan promover experiencias formativas en las que predomine la reflexión entre los alumnos, que promuevan una elaboración propia del conocimiento, a partir de los contenidos proporcionados, deberán cuidar no solo el tipo de propuestas a realizar, sino también los tiempos y modos en la presentación de las actividades, seguir el proceso de su desarrollo y cuidar los criterios de su evaluación, atendiendo a que todos los pasos en este proceso proporcionen la necesaria autonomía en el aprendizaje y aún la fortalezcan. (p. 111).

Así pues, atendiéndose a los asuntos que se han resaltado hasta este momento, la formación pedagógica que se propone tiene los siguientes objetivos:

- Garantizar al futuro docente la adquisición de los conocimientos teóricos y prácticos de la pedagogía, que le permitan desarrollarse y desempeñarse como docente en el contexto universitario, ofreciendo una enseñanza de calidad que contribuya al aprendizaje de los estudiantes y a su desarrollo autónomo. 
- Facilitar los recursos didácticos y tecnológicos que ayuden a enriquecer el proceso de la enseñanza, desde su planificación hasta su puesta en práctica, de manera que se propicie una participación activa de los estudiantes.

- Proporcionar los recursos necesarios para que seleccionen y elaboren diferentes técnicas que permitan llevar a cabo un proceso adecuado de assessment y realizar una adecuada evaluación del aprendizaje.

- Reforzar los principios éticos en la evaluación del aprendizaje de tal forma, que se respeten los derechos de los estudiantes en el proceso de enseñanza.

- Ofrecer los conocimientos necesarios acerca de las destrezas de comunicación interpersonal, de modo que se facilite el trato con los estudiantes y se fortalezca el trabajo en equipo con otros colegas.

- Proveer alternativas que le permitan al futuro docente seleccionar y organizar las evidencias necesarias acerca de la planificación y ejecución de su actividad docente y de la evaluación del aprendizaje que realiza.

En estos objetivos se encierran los contenidos específicos de la formación pedagógica, los cuales demuestran la complejidad del proceso de enseñanza, lo que fundamenta la estructuración del contenido de la formación en sí misma (ver tabla 1). Así pues, por medio de esta se pretende formar nuevos docentes universitarios que comiencen a ofrecer una nueva imagen a su profesión. Cabe resaltar que la propuesta de formación que se plantea podría considerarse una formación más, pero el enfoque con que el autor la estructuró, organizó y argumentó permite ver la aportación relevante de la formación. En efecto, las áreas formativas y sus contenidos, el orden lógico-pedagógico que se propone de estos y la combinación de perspectivas anglosajonas y europeas hacen que el proceso formativo sea enriquecedor y pertinente para el desarrollo profesional del profesor universitario de la actualidad. Así pues, cabe resaltar que con la misma minuciosidad con que se profundizó la formación, debe trabajarse para lograr la implantación de esta.

\section{Justificación del orden de las áreas que necesitan formación específica}

El orden que se propone para las áreas que necesitan formación específica (tabla 1), responde a la secuencia lógica que debe tomarse en cuenta al momento de iniciar e introducir a los futuros profesores universitarios en el contexto de la actividad docente. Para esto, debe dejarse claro que se parte de la idea de que el interesado en ejercer como docente, que participaría en la formación pedagógica previa que se propone, conoce de manera superficial o desconoce lo que implica pedagógicamente la actividad docente. Por tal razón, se comienza con el área "Formación general acerca del aprendizaje en la educación superior". Conocer cómo se aprende y las implicaciones que esto tiene en la docencia puede dar paso a una apertura hacia la comprensión de la importancia de ofrecer una enseñanza que responda a las necesidades de los estudiantes, respecto a su manera de aprender. En efecto, para que el profesor logre que sus estudiantes obtengan un aprendizaje significativo "debe tener un buen conocimiento acerca de estos, cuáles son 
Tabla 1. Áreas de necesidad para ejercer la docencia universitaria

\begin{tabular}{|c|c|c|}
\hline $\begin{array}{l}\text { Áreas que nece- } \\
\text { sitan formación } \\
\text { específica }\end{array}$ & $\begin{array}{c}\text { Temas } \\
\text { generales }\end{array}$ & Temas o contenidos específicos \\
\hline $\begin{array}{l}\text { Formación general } \\
\text { acerca del aprendi- } \\
\text { zaje en la educa- } \\
\text { ción superior }\end{array}$ & $\begin{array}{l}\text { Andragogía y edu- } \\
\text { cación superior } \\
\text { Proceso de apren- } \\
\text { dizaje }\end{array}$ & $\begin{array}{l}\text { Educación superior. Normativas generales y } \\
\text { específicas de la educación superior. Educa- } \\
\text { ción de adultos. } \\
\text { Proceso de aprendizaje. Estilos de aprendi- } \\
\text { zaje. Inteligencias múltiples. Neuropsicología } \\
\text { del aprendizaje. }\end{array}$ \\
\hline $\begin{array}{l}\text { Desarrollo de la en- } \\
\text { señanza }\end{array}$ & $\begin{array}{l}\text { Estrategias y recur- } \\
\text { sos para la ense- } \\
\text { ñanza } \\
\text { Recursos tecnológi- } \\
\text { cos en la enseñanza }\end{array}$ & $\begin{array}{l}\text { Enseñanza y aprendizaje activos. Estrategias } \\
\text { para enseñar. Control de tiempo. Arte de ha- } \\
\text { cer preguntas. } \\
\text { Recursos tecnológicos como parte del pro- } \\
\text { ceso de enseñanza. }\end{array}$ \\
\hline $\begin{array}{l}\text { Evaluación del } \\
\text { aprendizaje estu- } \\
\text { diantil }\end{array}$ & $\begin{array}{l}\text { Assessment y eva- } \\
\text { luación del apren- } \\
\text { dizaje en el contex- } \\
\text { to universitario } \\
\text { Recursos tecnológi- } \\
\text { cos en la evaluación } \\
\text { del aprendizaje }\end{array}$ & $\begin{array}{l}\text { Concepto de assessment, aplicación y técni- } \\
\text { cas para la recopilación de información. Cons- } \\
\text { trucción de instrumentos para la evaluación. } \\
\text { Estándares de la evaluación del aprendizaje. } \\
\text { Principios éticos en la evaluación del apren- } \\
\text { dizaje. Modelos para presentar los resulta- } \\
\text { dos de la evaluación. } \\
\text { Recursos tecnológicos en la preparación y } \\
\text { desarrollo de la evaluación del aprendizaje. }\end{array}$ \\
\hline $\begin{array}{l}\text { Planificación de la } \\
\text { enseñanza }\end{array}$ & $\begin{array}{l}\text { Estructuración de } \\
\text { la enseñanza: Pro- } \\
\text { ceso de planifica- } \\
\text { ción }\end{array}$ & $\begin{array}{l}\text { Adecuación de las competencias de los per- } \\
\text { files profesionales. Modelos para planificar. } \\
\text { Estructuración y organización de la enseñan- } \\
\text { za y la evaluación del aprendizaje. }\end{array}$ \\
\hline $\begin{array}{l}\text { Conocimiento di- } \\
\text { dáctico del conte- } \\
\text { nido }\end{array}$ & $\begin{array}{l}\text { Experiencias en di- } \\
\text { dáctica específica }\end{array}$ & $\begin{array}{l}\text { Recomendaciones específicas para la orga- } \\
\text { nización temática de las asignaturas. Aplica- } \\
\text { ción de los recursos didácticos en contextos } \\
\text { específicos. }\end{array}$ \\
\hline $\begin{array}{l}\text { Comunicación en el } \\
\text { contexto educativo } \\
\text { universitario }\end{array}$ & $\begin{array}{l}\text { Destrezas para la } \\
\text { comunicación en la } \\
\text { docencia }\end{array}$ & $\begin{array}{l}\text { Conceptos teóricos y prácticos acerca de la } \\
\text { comunicación verbal, no verbal y paraverbal } \\
\text { y su aplicabilidad en el contexto educativo. }\end{array}$ \\
\hline $\begin{array}{l}\text { Investigación edu- } \\
\text { cativa }\end{array}$ & $\begin{array}{l}\text { Investigación edu- } \\
\text { cativa en el contex- } \\
\text { to universitario }\end{array}$ & $\begin{array}{l}\text { Métodos y diseños de investigación en la edu- } \\
\text { cación. Redacción de propuestas de investi- } \\
\text { gación. Recopilación y análisis de datos cuan- } \\
\text { titativos y cualitativos. Utilización de progra- } \\
\text { mas para el análisis de datos. Redacción de } \\
\text { informes. Publicación de artículos en revis- } \\
\text { tas profesionales. Utilidad de la investigación } \\
\text { educativa. }\end{array}$ \\
\hline $\begin{array}{l}\text { Evaluación de la } \\
\text { actividad docente }\end{array}$ & $\begin{array}{l}\text { Práctica en docen- } \\
\text { cia universitaria }\end{array}$ & $\begin{array}{l}\text { Estructuración, organización y ofrecimiento } \\
\text { de una asignatura. Recopilación de eviden- } \\
\text { cias acerca de la planificación y ejecución de } \\
\text { la enseñanza. Evidencias del assessment y } \\
\text { evaluación del aprendizaje con sus resulta- } \\
\text { dos discutidos. Reflexión acerca de la expe- } \\
\text { riencia en la práctica en docencia. }\end{array}$ \\
\hline
\end{tabular}


Ios conocimientos previos que estos traen, cuál es el estilo de aprendizaje que debe utilizar" (Ávila, Quintero, \& Hernández, 2010, p. 74). De esta forma, el futuro profesor va haciéndose la idea de lo que debe tener en cuenta cuando le corresponda trabajar como docente, especialmente, en el contexto universitario, donde se trabaja con un estudiantado de características muy específicas, distintas de otros niveles de enseñanza. En relación con esto, Verdejo y Medina (2009) afirmaron que

ciertamente, uno de los grandes planteamientos de la pedagogía y de la Andragogía moderna consiste en que como aprendices construimos nuestro conocimiento, razón por la cual es imprescindible aprender cómo se aprende y de qué manera se facilita el aprendizaje, hasta alcanzar el conocimiento de nuestros estilos propios de aprender. (p. 72).

Una vez conocido y comprendido el proceso de aprendizaje, puede procederse, de una mejor manera, a aplicar tales conocimientos en las estrategias para enseñar, que se aborda en el área "Desarrollo de la enseñanza". Así pues, al ejemplificarse las estrategias para enseñar puede observarse la relación que estas tienen con el proceso de aprendizaje. Igualmente, sucede con el área acerca de la "Evaluación del aprendizaje estudiantil". Esta introduce temas tales como: la taxonomía del dominio cognoscitivo, el assessment del aprendizaje y la evaluación del aprendizaje, entre otros. Estos temas pueden aplicarse, de una mejor manera, en la práctica al relacionarlos con el proceso de aprendizaje. Por esta razón, Paricio (2010) aseveró que "la diversidad en el tipo de actividades programadas favorece la implicación, la atención a la diversidad de estilos de aprendizaje y genera resultados de aprendizaje más ricos" (p. 29). Por otro lado, cabe indicar que en ambas áreas, se incluye una parte acerca de la utilidad de los recursos tecnológicos para la preparación de materiales para la enseñanza o de instrumentos para el assessment, la evaluación del aprendizaje y para el enriquecimiento y complementación de la actividad docente. A través de estos, se trata de acercar al futuro profesor a una serie de recursos, pero haciéndole ver la pertinencia y utilidad de estos para el mejoramiento de la práctica de la enseñanza (Cabero, 2014). En fin, lo significativo de estas es que se abordan en consonancia con el área informativa (i.e., enseñanza y evaluación), lo cual refleja conexión y correspondencia entre los contenidos y justifica su secuencia lógico-práctica.

A pesar de que la "Planificación de la enseñanza" es el inicio de todo trabajo pedagógico, aquí se incluye en cuarto lugar. Esto responde a que se presume que antes de planificar el proceso de enseñanza, deben conocerse los elementos necesarios para llevarlo a cabo. Es decir, para poder planificar adecuadamente y con consciencia pedagógica, primero debe conocerse cómo se aprende, qué estrategias pueden utilizarse para enseñar y cómo se evalúa el aprendizaje de los estudiantes. Si no se cuenta con los conocimientos necesarios, no puede hacerse una planificación adecuada y coherente que, a su vez, facilite la ejecución de la enseñanza. En relación con esto, debe tenerse en cuenta que esta propuesta para la formación pedagógica del profesor universitario se dirige a profesionales que deseen introducirse a la docencia universitaria, por lo cual, se presume que tengan poco o ningún conocimiento pedagógico. Así, se ve necesario trabajar con ellos de 
una forma diferente a la que se acostumbra normalmente, pues el aprendizaje deberá guiarse igualmente, como si fueran alumnos de primer año en la Facultad de Educación. Por esta razón, Garita (2008) indicó que

ahora que tenemos un horizonte más amplio de la educación de adultos, en cuanto a aprender a aprender y las diversas formas de inteligencia existentes, el reto es mejorar nuestra didáctica universitaria, en la planificación no solo conceptual de los conocimientos o las prácticas, sino en la inspiración de los educandos, pues la verdad no solo debe informar, sino inspirar. (p. 33).

Más adelante en la formación, se incluye un área acerca del "Conocimiento didáctico del contenido". En este, se espera que los participantes trabajen con compañeros de especialidades relacionadas, en torno a experiencias en didáctica específica que les permitan observar la aplicabilidad de lo que trabajaron en las áreas anteriores. Así pues, observando ejemplos reales de la actividad docente de futuros colegas, podrían visualizar, de una mejor manera, la pertinencia de la formación pedagógica y su utilidad en sus respectivas especialidades. Debe mencionarse, que esta área no se incluye antes por la especificidad de este y para que se trabaje de una forma más personalizada. Respecto a esto, cabe mencionar que "el aprendizaje de la enseñanza se favorece cuando las perspectivas de la enseñanza y aprendizaje que se proponen desde el programa formativo son modeladas por formadores de profesores en su propia práctica" (González \& Fuentes, 2011, p. 63). Además, el encuentro de los futuros docentes puede propiciar espacios donde "al debatir sobre actividades y tareas de aprendizaje, así como su secuencia, los docentes exponen sus propios principios y teorías acerca de cómo se enseña y se aprende" (Marcelo, Yot, Sánchez, Murillo, \& Mayor, 2011, p. 197).

En la siguiente área de necesidad, "Comunicación en el contexto educativo universitario", se plantea que un experto en destrezas para la comunicación en la docencia pueda presentar a los futuros profesores los elementos necesarios para que se lleve a cabo un proceso de enseñanza con una comunicación efectiva. Una vez que se aborden los procesos de planificación, de la enseñanza y de la evaluación del aprendizaje, de manera general y específica, puede trabajarse con la comunicación. De esta forma, pueden visualizarse, desde otra perspectiva, tales procesos y profundizar en los elementos que se requieren para una comunicación efectiva. En efecto, "la presentación oral debe apoyarse en una oratoria eficaz en la que tanto la información verbal como la no verbal sea ajustada: el lenguaje exacto y la vocalización y expresión correctas" (Gallego, 2008, p. 12).

Respecto de la "Investigación educativa", se incluye un área en la cual se pretende que los participantes de la formación profundicen en torno a la investigación, pero desde una perspectiva educativa. Justamente, en esta área se encierran temas que se relacionan con el diseño de una investigación dentro de la misma actividad docente, en la cual puede indagarse en asuntos que se relacionen con cuestiones pedagógicas. De esta forma, los futuros profesores podrían tener la oportunidad de contribuir al avance del conocimiento didáctico del contenido, a la vez que difunden sus investigaciones en diferentes foros de interés para la comunidad investigativa, tanto institucional como estatal e internacional. Así 
pues, Bolívar y Caballero (2008) argumentaron acerca de este asunto de la investigación educativa, de la siguiente manera:

La excelencia visible en la enseñanza conjuga las acciones excelentes y expertas del buen docente con el interés por difundir y hacer públicos los hallazgos obtenidos en la investigación sobre enseñanza y aprendizaje. Se trata de extender los resultados de la propia investigación, propiciando su impacto en la práctica educativa del resto del profesorado. (p. 5).

Finalmente, se incluye el área "Evaluación de la actividad docente". Allí se consiente que se ponga a prueba la capacidad docente del futuro profesor y se someta a un proceso de evaluación, a través de una práctica en docencia universitaria en un contexto real. Este es un componente innovador, porque permite que todo lo que se haya aprendido y perfeccionado a lo largo de la formación se ponga en práctica. En efecto, "solo cuando la práctica va acompañada de formación y de revisión es posible conocer más a fondo las entrañas de la docencia y la dinámica de aprendizaje de los alumnos" (Zabalza \& Zabalza, 2010, p. 61). De esta forma, el futuro profesor puede tener una experiencia previa en docencia, lo que puede contribuir al comienzo de su desarrollo profesional. Es significativo resaltar que, durante esta experiencia, se le asignará un profesor, director/supervisor de práctica, que guíe y dé seguimiento a la actividad docente. En el caso de que la formación se llevara a cabo de manera inicial para profesores noveles, esta área podría sustituirse por la aplicación continua en tareas de ejecución específicas en relación con el área de necesidad en el que se esté trabajando a lo largo de la formación.

La formación pedagógica del profesorado universitario es tan importante como su formación académica (i.e., especialidad). Es la base de un proceso de enseñanza que promueva el aprendizaje y ayude al estudiante a desarrollar las competencias necesarias para desempeñarse en su futuro profesional. La formación pedagógica podría facilitar el entendimiento de las exigencias que se dan en torno al proceso de enseñanza. De esta forma, estas no se observan como carga adicional, sino como parte importante y necesaria del mismo proceso de enseñanza. Al mismo tiempo, se promueve el mejoramiento de las prácticas en favor del aprendizaje del estudiante, lo que puede redundar en la calidad de la enseñanza. En efecto, un profesor que conozca muy bien el contenido de sus asignaturas, se complementa cuando desarrolla las destrezas que le permiten impartir debidamente la enseñanza. En relación con estas ideas, López, González y León (2014) afirmaron que

el perfil docente derivado del mismo responde a un profesional que desarrolla su actividad sobre la base de una labor planificada de forma sistemática y con suficiente antelación, donde la información a transmitir está ligada directamente con las competencias profesionales del trabajo para el que capacita la titulación en la que se encuentra y que emplea recursos, metodologías y estrategias didácticas en un contexto específico de enseñanza-aprendizaje donde la planificación docente, la gestión del tiempo y del espacio, los sistemas de evaluación y la interacción con el alumnado juegan un papel importante. (p. 146) 
Así pues, dada la necesidad de reformar el proceso educativo en la universidad, las instituciones deben promover la formación permanente de su profesorado facilitándole los recursos necesarios para esta. Esto podría establecer una cultura pedagógica entre los profesores, lo que fomentaría una revalorización de la docencia a nivel institucional.

\section{Rol de las instituciones universitarias respecto a la formación pedagógica de su profesorado}

Las instituciones universitarias deben promover, paulatinamente, una cultura de cambio en torno a este y otros asuntos que atañen a la calidad de la enseñanza, desde el punto de vista del profesor, en primer lugar. Esto implica que las autoridades universitarias muestren interés en ofrecer una enseñanza que ponga énfasis en una perspectiva activa del aprendizaje estudiantil. De esta forma, se involucran de tal manera, que se observa un compromiso y una disposición para colaborar con todo lo que sea necesario para trabajar con este asunto. No basta con exigir, también debe ofrecerse, facilitarse, disponerse. En efecto, reconociéndose las responsabilidades de las instituciones universitarias, lo que refleja su autonomía, pueden realizarse diferentes esfuerzos para garantizar la calidad de la enseñanza, de entre los cuales la formación pedagógica del profesorado debe ser prioridad. Así pues, se comienza a trabajar por y con aquel que dirige el proceso de enseñanza, lo que puede contribuir a que los estudiantes puedan tener una mejor guía de su aprendizaje. Pues "proporcionando al profesorado más información en cómo enseñar con eficacia, las instituciones pueden ayudar a crear una mayor satisfacción del profesorado" (Meyer \& Murrell, 2014, sección de Recomendaciones, párr. 5). Satisfacción que manifiestan profesores que participan de formación pedagógica, que según Palomeque-Forero, Sánchez-Botero y MonroyRamírez (2014) se da "por el nivel de manejo de las disciplinas que han adquirido y por la concientización sobre la necesidad de actualización y renovación constante en su labor" (p. 71).

Por tal razón, las instituciones universitarias deben promover el cambio, demostrando la pertinencia que tiene la formación pedagógica de los profesores. No obstante, para que sea creíble una formación que se proponga "debe ofrecer una perspectiva contrastada y de autoridad con respecto a los principios de mejora de la enseñanza universitaria" (Rué \& de Corral, 2007, p. 20). Cabe señalar que esto no debe hacerse simplemente por una imposición que carezca de fundamentos. Debe hacerse a través de un proceso en el que se demuestre la necesidad (evidenciándose esta), se motive (mostrándose resultados de otros) y se propicie algún tipo de mérito que valore el desarrollo profesional de los profesores. Pues, como afirmaron Akkerman y Bakker (2011), ser en un área específica del saber puede impedir que se tengan experiencias en otras áreas, especialmente en profesores que se cierran y no aceptan ser novatos en otra área. Esto se da porque deben cruzarse los límites entre el dominio de su especialidad y el dominio de conocimientos pedagógicos. 
De Miguel (2003) afirmó que "solamente cuando existe un compromiso claro y explícito de los responsables académicos respecto a la formación del profesorado, podemos considerar que la mejora de la calidad de la enseñanza constituye un objetivo prioritario en nuestras instituciones" (p. 26). Esta afirmación permite evidenciar lo que plantea en relación a que las instituciones universitarias deben involucrarse en la formación pedagógica de sus profesores. De esta forma, pueden demostrar su interés hacia el ofrecimiento de una enseñanza de calidad. Por tanto, "la Universidad cuenta con un profesorado con una vasta preparación como especialistas en las diferentes áreas disciplinares, pero que, por el contrario, presentan una deficiente formación pedagógica y en habilidades sociales" (Sánchez \& Mayor, 2006, p. 924). Por esto, de nada sirve contratar profesores muy competentes en sus respectivas especialidades si no pueden guiar a los estudiantes hacia el aprendizaje. En efecto, debe saber facilitarse el conocimiento a través de una enseñanza bien dirigida, que propicie una comunicación eficaz y un trabajo activo del estudiante.

Asimismo, las instituciones universitarias, como centros de formación estudiantil, deben velar por la calidad de la enseñanza que se ofrece. Esto no debe hacerse tan solo desde la mejora institucional, sino que debe hacerse desde la eficacia de la enseñanza, como principal evidencia acerca de la calidad de esta. Justamente, "los dos grandes parámetros que determinan la calidad de una Universidad son, por un lado, la calidad de los alumnos, y por otro, la calidad de los profesores" (Muñiz \& Fonseca-Pedrero, 2008, p. 14). No obstante, también, se entiende que hay otros aspectos como las instalaciones físicas, los recursos tecnológicos (e.g., recursos audiovisuales), la organización de los programas de las titulaciones académicas, entre otros aspectos, que suelen tomarse en cuenta para evidenciar la calidad. Sin embargo, en este artículo se ha hecho hincapié en la importancia de observarse la calidad de la enseñanza desde sí misma, desde su eficacia; donde se implica directamente la actividad docente. Por esto, se indagó este asunto desde la figura del profesor, quien tiene la responsabilidad mayor en el proceso de enseñanza, porque es quien facilita directamente el conocimiento. No obstante, las instituciones universitarias, desde los encargados de los asuntos académicos o desde sus facultades y departamentos académicos, han de involucrarse de tal manera que se preste atención e importancia a la enseñanza, compartiendo así su responsabilidad con los profesores. Así pues, debe tomarse en cuenta que hay que contar con profesores que demuestren competencia, tanto en su área de especialidad como en destrezas pedagógicas. Esto permite fortalecer la profesionalidad del profesor ante su responsabilidad primera: el aprendizaje de los estudiantes, como facilitador y guía del mismo.

La calidad de la enseñanza es un asunto muy actual del que suele hablarse pero, más allá del discurso, debe propiciarse un esfuerzo en las instituciones universitarias para garantizarla. Pese al auge que va observándose en torno a este asunto, todavía queda mucho camino por andar. En muchas universidades, la concepción del proceso de enseñanza todavía tiene la sombra de un sistema que pone como centro al profesor. El estudiante, mayormente, escucha y toma apuntes que luego debe vaciar literalmente en un examen (i.e., con las mismas 
palabras que el profesor utilizó, sin propiciarse un proceso de comprensión), luego de trabajarse en un proceso de memorización forzada que no necesariamente conduce a un aprendizaje. De acuerdo con Verdejo y Medina (2009), comprender implica un entendimiento de lo que se transmite, pudiendo utilizarse de alguna forma el contenido o las ideas que se contengan. Este proceso implica que se guarde fidelidad al contenido original, aunque se comunique de manera diferente; es decir, parafraseándose o codificándose la comunicación en otro lenguaje. Esto último, evidencia la capacidad de entendimiento, porque el estudiante puede expresar en sus palabras la misma idea sin temer que se pierda la esencia del contenido.

En consecuencia, todos estos esfuerzos deben desembocar en un compromiso institucional que promueva el cumplimiento de las exigencias acerca de la calidad de la enseñanza. Es importante que las instituciones demuestren su compromiso con estos asuntos a través de una participación activa, siendo acompañantes más que impositoras. Pues, "la participación institucional resulta necesaria para la mejora general de la calidad universitaria lo que significa dedicación y compromiso institucional" (Vázquez, Colom, \& Sarramona, 1998, p. 76). De esta forma, se observa que se trabaja en colaboración hacia un mismo fin: la calidad de la enseñanza. Los profesores deben observar que no trabajan solos, que hay comunicación entre la administración universitaria y las facultades académicas. Así, la universidad se fortalece a la vez que se proyecta como una institución que propicia una formación de profesionales con calidad.

\section{Conclusiones generales}

Una formación como la que se presentó en este artículo, responde a lo que Baute e Iglesias (2014) plantearon; pues, luego de un proceso de planificación, estructuración y justificación de la misma, resulta "un sistema de formación pedagógica perfeccionado, fortalecido y desarrollador de conocimientos, habilidades, valores y modos de actuación del profesor universitario en correspondencia con las demandas sociales a las universidades" (p. 80). Así pues, acerca de la formación pedagógica del futuro profesor, a partir de las ideas que se han expuesto a lo largo de los hallazgos con su debida argumentación, puede concluirse lo siguiente:

- La formación pedagógica del futuro profesor, especialmente, una formación previa o antes de ejercer como docente, es necesaria, importante y pertinente.

- La formación previa marca el comienzo de una nueva actividad respecto al conocimiento pedagógico de los profesores universitarios. Es un precedente que puede hacer cambiar la mentalidad de muchos docentes, que no rinden honor a la profesión que ejercen.

- La pertinencia de una formación inicial radica en que el futuro profesor podría familiarizarse, previamente, con todas las responsabilidades que acompañan su rol como docente universitario y desempeñarse de una mejor manera en el contexto educativo real. 
- Lo importante de la formación pedagógica que se propuso es que los contenidos de la misma permiten abarcar, de forma holística, el proceso de enseñanza desde el punto de vista de la calidad de la actividad docente. Solo falta que se tome la iniciativa para llevarla a cabo. No obstante, para esto requiere de un equipo de profesionales, altamente cualificados, que sirvan como formadores. Así pues, este equipo debe vivir lo que enseña, ser ejemplo de lo que promueve y demostrar conocimientos respecto a todo lo que enseña y exige a los participantes.

- En la estructura y secuencia de los contenidos de la formación, se toma en cuenta, de una forma lógico-pedagógica, los conocimientos necesarios para cada una de las áreas formativas. En lo que se refiere a los contenidos específicos de la formación inicial que se propuso, puede afirmarse que se observa completitud en referencia a la actividad docente.

- La formación pedagógica del profesor universitario es un asunto que no termina de concretarse, a pesar de que se haga hincapié en la necesidad de formarse para desempeñarse adecuadamente en el contexto universitario.

Acerca de cómo debe trabajarse en las instituciones universitarias para garantizar la calidad de la enseñanza, puede concluirse lo siguiente:

- La calidad de la enseñanza es un trabajo de todos en la universidad. No obstante, para garantizar una enseñanza de calidad se necesita de una buena comunicación que facilite el seguimiento de la actividad docente de los profesores, pero que, al mismo tiempo, refleje apoyo por parte de la misma institución universitaria.

- A la universidad le corresponde vigilar por la calidad de la enseñanza, lo cual, solo puede lograrlo involucrándose en los asuntos que se relacionan con la formación pedagógica del profesor y su desarrollo profesional, respecto al proceso mismo de la enseñanza.

- Si las instituciones universitarias desean promover una enseñanza de calidad deberán establecer una serie de requisitos que, al menos, garanticen la cualificación docente del profesorado para que el proceso de enseñanza se lleve a cabo de una forma eficaz.

En síntesis, puede afirmarse que, aunque se ha estado haciendo mucho para hacer ver la importancia de la formación pedagógica del profesorado universitario, todavía queda mucho por recorrer. Este es un tema que se aborda desde distintos puntos de vistas, pero deben llevarse a cabo mayores esfuerzos para evidenciar los beneficios de la formación pedagógica. En efecto, teniéndose una idea real acerca de la pertinencia de la formación y de lo que puede facilitar a un docente para desempeñarse como tal, es lo que podría provocar que se tome con mayor seriedad y compromiso este asunto. Así pues, queda afirmar que las instituciones universitarias tiene un rol crucial en esto, pues son las que se sirven del trabajo que desempeñan los profesores, principalmente, respecto al proceso de enseñanza. Por tal razón, debe profundizarse en este aspecto, con el propósito de fortalecer o despertar el interés hacia las competencias docentes y sus implicaciones para la calidad institucional, en general. 


\section{Recomendaciones para investigaciones futuras}

Las recomendaciones para investigaciones futuras surgieron a partir de asuntos que, durante el transcurso de esta investigación, despertaron el interés del investigador para profundizar en ellos, pero no formaban parte de los propósitos de la investigación. En efecto, la delimitación en toda investigación hace que asuntos como estos queden fuera del alcance investigativo, lo que a su vez puede propiciar nuevos estudios que permitan el avance del conocimiento en áreas más específicas. Entre las recomendaciones que se ofrecen para investigaciones futuras se encuentran las siguientes:

- Estudiar la disposición de los profesores universitarios para formarse pedagógicamente, mantener actualizados sus conocimientos pedagógicos y llegar a desarrollarse profesionalmente como docentes de un área específica del conocimiento.

- Determinar y comparar la efectividad de los programas de formación pedagógica para profesores universitarios que existen actualmente en las universidades españolas, ya sean de libre acceso o de acceso limitado.

- Comparar el desempeño de profesores con formación pedagógica con el desempeño de profesores sin formación pedagógica y su efecto en el proceso de enseñanza, en instituciones universitarias que cuenten con programas para la formación de su profesorado.

- Auscultar cuánto conocen los profesores universitarios el proceso de aprendizaje en adultos y su relación con la eficacia en la enseñanza.

- Examinar el conocimiento que tienen los profesores universitarios acerca de los principios éticos en la evaluación del aprendizaje estudiantil.

- Indagar acerca de la estructura, la organización, el procedimiento y la efectividad de los programas y sistemas universitarios de evaluación de la actividad docente de los profesores universitarios.

- Profundizar en torno a la opinión del profesorado universitario acerca de la profesionalización de la docencia.

- Investigar acerca de la aplicación de la legislación correspondiente al acceso de los profesores a los cuerpos docentes universitarios y su efectividad en torno a la calidad de la enseñanza.

- Analizar cómo impacta el proceso de evaluación de la práctica docente en el profesorado universitario desde la perspectiva de la calidad de la enseñanza, tanto por sus pares como por los estudiantes, en los distintos niveles de la educación superior. 


\section{Referencias bibliográficas}

Aciego, R., Martín, E., \& García, L. (2003). Demandas del profesorado de su formación docente. Revista Interuniversitaria de Formación del Profesorado, 17(2), 53-77.

Akkerman, S. F., \& Bakker, A. (2011). Boundary Crossing and Boundary Objects. Review of Educational Research, 81(2), 132-169. doi: 10.3102/0034654311404435.

Altheide, D., Coyle, M., DeVriese, K., \& Schneider, C. (2008). Emergent qualitative document analysis. En S. N. Hesse-Biber \& P. Leavy (Eds.), Handbook of emergent methods (pp. 127149). New York: The Guilford Press.

Álvarez, I. (2008). Evaluación del aprendizaje en la universidad: Una mirada retrospectiva y prospectiva desde la divulgación científica. Revista Electrónica de Investigación Psicoeducativa, 14(6), 235-272.

Álvarez, J. D., Tortosa, M. T., Moncho, A., Pareja, J. M., Francés, J., Vega, A. M., \& Alonso, N. (2012). La formación docente universitaria. Análisis del programa de formación de la Universidad de Alicante. Revista Congreso Universidad, I(2), 1-13.

Aquino, S. P., Magaña, D. E., \& Rosas, J. A. (2013). Formación del profesorado universitario: vinculación con el desarrollo profesional e institucional. Revista Congreso Universidad, II(3), 1-11.

Aramburuzabala, P., Martínez-Garrido, C., \& García-Peinado, R. (2013). La formación del profesorado universitario en España: evolución y perspectivas. Educación, XXII(43), 7-25.

Asensio, J. M. (2000). La formación docente en y para la complejidad. Teoría y Educación, $12,29-43$.

Ávila, A., Quintero, N., \& Hernández, G. (2010). El uso de estrategias docentes para generar conocimientos en estudiantes de educación superior. Omnia, 16(3), 56-76.

Barberà, E. (2008). La incorporación de las TIC en las nuevas propuestas metodológicas: el portafolio del estudiante. En I. Rodríguez Escanciano (Ed.), El nuevo perfil del profesor universitario en el EEES: claves para la renovación metodológica (pp. 115-125). Valladolid, España: Universidad Europea Miguel de Cervantes.

Baume, C., \& Baume, D. (2001). Un plan nacional de formación y acreditación para profesores universitarios. Revista de Docencia Universitaria, 1(3). Recuperado de http:// revistas.um.es/red_u/article/view/11591/ 11171.

Baute, L., \& Iglesias, M. (2014). Sistematizar la formación pedagógica del profesor universitario. Propuesta de un diseño. Universidad y Sociedad, 6(1), 75-80. Recuperado de http:/ /rus.ucf.edu.cu/.

Biggs, J. (2008). Calidad del aprendizaje universitario (3a. ed.). Madrid: Narcea.

Biscarri, J., Filella, G., \& Jové, G. (2006). Factores relacionados con la percepción de la calidad docente del profesorado universitario. Revista Interuniversitaria de Formación del Profesorado, 20(3), 287-309. 
Bolívar, A., \& Caballero, K. (2008). Cómo hacer visible la excelencia en la enseñanza universitaria. Revista Iberoamericana de Educación, 46(8), 1-10.

Caballero, K. (2013, mayo-agosto). La formación del profesorado universitario y su influencia en el desarrollo de la actividad profesional. Revista de Docencia Universitaria. REDU, 11(2), 391-412.

Cabero, J. (2014). Formación del profesorado universitario en TIC. Aplicación del método Delphi para la selección de los contenidos formativos. Educación XX1, 17(1), 109-132. doi: 10.5944/educxx1.17.1.10707.

Cáceres, M., Lara, L., Iglesias, M., García, R., Bravo, G., Cañedo, C., \& Valdés, O. (2003). La formación pedagógica de los profesores universitarios: Una propuesta para el proceso de profesionalización del docente. Revista Iberoamericana de Educación. Recuperado de http://www.rieoei.org/deloslectores/475Caceres.pdf.

Cano, R., \& Revuelta, C. (1999). La formación permanente del profesorado universitario. Revista Electrónica Interuniversitaria de Formación del Profesorado, 2(1), 55-62. Recuperado de http://www.uva.es/aufop/ publica/revelfop/99-v2n1.html.

Cebrián, M. (2008). Los procesos de innovación didáctica en el marco del Espacio Europeo de Educación Superior. En I. Rodríguez Escanciano (Ed.), El nuevo perfil del profesor universitario en el EEES: claves para la renovación metodológica ( $p$. 19-35). Valladolid: Universidad Europea Miguel de Cervantes.

Concepción, P. M., Fernández, M., \& González, D. (2014). La construcción de un cuestionario para la detección de necesidades formativas del profesorado novel. Pedagogía Universitaria, XXI(1), 1-29.

Corbin, J., \& Strauss, A. (2008). Basics of qualitative research (3a. ed.). Los Ángeles, CA: SAGE Publications.

Creswell, J. W. (2012). Educational research: Planning, conducting, and evaluating quantitative and qualitative research (4a. ed.). Upper Saddle River, NJ: Merrill Prentice Hall.

de la Calle, M. J. (2004). El reto de ser profesor en el contexto de la convergencia europea: La formación pedagógica como necesidad. Revista Interuniversitaria de Formación del Profesorado, 18(3), 251-258.

de la Cruz, M. A. (2000). Formación pedagógica inicial y permanente del profesor universitario en España: Reflexiones y Propuestas. Revista Interuniversitaria de Formación del Profesorado, 38, 19-36.

de la Cruz, M. A. (2003). Necesidad y objetivos de la formación pedagógica del profesor universitario. Revista de Educación, 331, 35-66.

de la Herrán, A. (2003). Didáctica universitaria, la cara dura de la universidad. En A. de la Herrán (Coord.), El siglo de la educación: Formación evolucionista para el cambio social (pp. 327-351). Huelva: Hergué.

de Miguel, M. (2003). Calidad de la enseñanza universitaria y desarrollo profesional del profesorado. Revista de Educación, 331, 13-34. 
de Miguel, M. (Dir.). (2006). Modalidades de enseñanza centradas en el desarrollo de competencias: Orientaciones para promover el cambio metodológico en el marco del EEES. Asturias: Ediciones de la Universidad de Oviedo.

Fernández, A. (2008). La formación inicial del profesorado universitario: El título de especialista universitario en pedagogía universitaria de la Universidad Politécnica de Valencia. Revista Interuniversitaria de Formación del Profesorado, 63(22,3), 161-187.

Gairín, J. (2011). Formación de profesores basada en competencias. Bordón, 63(1), 93108.

Galán, A. (2007). La formación del profesorado y la evaluación de la docencia. En A. Galán (Ed.), El perfil del profesor universitario: Situación actual y retos de futuro (pp. 60-82). Madrid: Ediciones Encuentro.

Gallego, M. J. (2008). Comunicación didáctica del docente universitario en entornos presenciales y virtuales. Revista Iberoamericana de Educación, 46(1), 1-16.

García-Valcárcel, A. (2001). La función del docente universitario, su formación y desarrollo profesional. En A. García-Valcárcel (Coord.), Didáctica universitaria (pp. 1-27). Madrid: La Muralla.

Garita, L. A. (2008). La didáctica universitaria en el contexto de la andragogía: Aprender a aprender en la educación de personas adultas. TEC Empresarial, 2(2), 29-33.

González, M., \& Fuentes, E. J. (2011). El practicum en el aprendizaje de la profesión docente. Revista de Educación, 354, 47-70.

Hernández, R., Fernández-Collado, C., \& Baptista, P. (2014). Metodología de la investigación (6a. ed.). México: McGraw-Hill.

Ibarra, M. S., \& Rodríguez, G. (2010). Aproximación al discurso dominante sobre la evaluación del aprendizaje en la universidad. Revista de Educación, 351, 385-407.

Joint Committee on Standards for Educational Evaluation (2003). The student evaluation standards: How to improve evaluations of students. Thousand Oaks, CA: Corwin.

Karjalainen, A., Alha, K., \& Jutila, S. (2009). Revisión de programas educativos: ¿Qué es lo esencial? En C. Vizcarro (Ed.), Buenas prácticas en docencia y política universitarias (pp. 195-226). Madrid: Edisofer.

Knapper, C. (2009). Investigación sobre la enseñanza y el aprendizaje: Aplicar lo que sabemos. En C. Vizcarro (Ed.), Buenas prácticas en docencia y política universitarias (pp. 31-39). Madrid: Edisofer

Krippendorff, K. (2004). Content analysis: An introduction to its methodology (2a. ed.). Thousand Oaks, CA: SAGE Publications.

Leonetti, A.L., Medina, E., Alday, M., Sowter, C., Pandiella, S., Quiroga, R. et al. (2010). La formación docente y la calidad de la educación en el marco de la enseñanza para la comprensión. Recuperado de http://www.feeye.uncu.edu.ar/web/posjornadasinve/ area4/ Formacion $\% 20$ docente $\% 20 y \% 20$ evaluacion $\% 20$ en $\% 201$ a $\% 20$ formacion $\% 20$ docente/ 104\%20-\%20Leonetti\%20y\%20Otras\%20-\%20UN\%20San\%20Juan.pdf. 
López Camps, J. (2005). Planificar la formación con calidad. Madrid, España: CISSPRAXIS. López Noguero, F. (2005). Metodología participativa en la enseñanza universitaria. Madrid: Narcea.

López, A. B., González, I., \& de León, C. (2014). Perfil de un buen docente. Aplicación de un protocolo de evaluación de las competencias del profesorado universitario. Revista Electrónica Interuniversitaria de Formación del Profesorado, 17(1), 133-148. doi: 10.6018/ reifop.17.1.190531.

Lucarelli, E. (2008). Asesoría pedagógica y cambio en la universidad. Profesorado. Revista de Currículum y Formación del Profesorado, 12(1), 1-14.

Marcelo, C. \& Vaillant, D. (2009). Desarrollo profesional docente: ¿Cómo se aprende a enseñar? Madrid: Narcea.

Marcelo, C., Yot, C., Sánchez, M., Murillo, P., \& Mayor, C. (2011). Diseñar el aprendizaje en la universidad: Identificación de patrones de actividades. Profesorado. Revista de currículum y formación del profesorado, 15(2), 181-198. Recuperado de http://www.ugr.es/local/ recfpro/ rev151COL1.pdf.

Martínez, J. A. (2010). El Espacio Europeo de Educación Superior (EEES) y nuevo rol del estudiante universitario. Cuadernos de Educación y Desarrollo, 2(16). Recuperado de http:/ /www.eumed.net/rev/ced/16/ jamg.htm.

Mas, O., \& Ruiz, C. (2007). El Profesor universitario en el nuevo Espacio Europeo de Educación Superior: Perfil competencial y necesidades formativas. Conferencia presentada en el Primer Congreso Internacional Nuevas Tendencias en la formación permanente del profesorado. Barcelona, España: Universidad de Barcelona. Recuperado de http:// webs2002.uab.es/paplicada/DOCyPDF/ MASyRUIZ_FODIP2007_v2.pdf.

Mauri, T., Coll, C., \& Onrubia, J. (2007, febrero). La evaluación de la calidad de los procesos de innovación docente universitaria: Una perspectiva constructivista. Revista de Docencia Universitaria, 1. Recuperado de http://redu.um.es/Red_U/1/.

McMillan, J. H. (2012). Educational research: Fundamentals for the consumer (6a. ed.). Boston, MA: Allyn and Bacon.

McMillan, J. H. (2014). Classroom assessment: Principles and Practice for effective standarsbased instruction (6a. ed.). Boston, MA: Allyn and Bacon.

Mérida, R. (2006). Nueva percepción de la identidad profesional del docente universitario ante la convergencia europea. Revista Electrónica de Investigación, 8(1). Recuperado de http://redie.uabc.mx/vol8no1/ contenido-merida.html.

Meyer, K. A., \& Murrell, V. S. (2014). A National Study of Training Content and Activities for Faculty Development for Online Teaching. Journal of Asynchronous Learning Networks, 18(1).

Monedero, J. J. (2007). El diseño de los materiales educativos ante un nuevo reto en la enseñanza universitaria: El Espacio Europeo de Educación Superior (EEES). Revista Interuniversitaria de Formación del Profesorado, 21(1), 51-68. 
Monereo, C. (2013). La investigación en la formación del profesorado universitario: hacia una perspectiva integradora. Infancia y Aprendizaje. Journal for the Study of Education and Development, 36(3), 281-291. doi: 10.1174/021037013807533052.

Moreno, T. (2009). La evaluación del aprendizaje en la universidad. Tensiones, contradicciones y desafíos. Revista Mexicana de Investigación Educativa, 14(41), 563-591.

Mueller, J. (2005). The authentic assessment toolbox: Enhancing student. Learning throught online faculty development. Journal of Online Learning and Teaching, 1(1). Recuperado de http://jolt.merlot.org/ vol1no1/mueller.htm.

Muñiz, J., \& Fonseca-Pedrero, E. (2008). Construcción de instrumentos de medida para la evaluación universitaria. Revista de Investigación en Educación, 5, 13-25.

Muñoz, I. (2004). Evaluación de la competencia docente del profesor universitario. En J. C. Torre \& E. Gil (Eds.), Hacia una enseñanza centrada en el aprendizaje (pp. 321-347). Madrid: Edisofer.

Newman, J. H. (1996). The idea of a university. [Discursos sobre el fin y la naturaleza de la educación universitaria]. Navarra: Ediciones Universidad de Navarra.

Noguera, J. (2001). La formación pedagógica del profesorado universitario. Bordón, 53(2), 269-277.

Ordóñez, C. L. (2004). Pensar pedagógicamente desde el constructivismo: De las concepciones a las prácticas pedagógicas. Revista de Estudios Sociales, 19, 7-12.

Pabón, L. C., Ofra, M., Garzón, R., del Riesgo, L., Pinzón, M. L. \& Salamanca, A. L. (2009). Estrategias pedagógicas como herramienta educativa: "la tutoría y el proceso formativo de los estudiantes". Revista Iberoamericana de Educación, 50(3), 1-16.

Palomeque-Forero, L. A., Sánchez-Botero, C. H., \& Monroy-Ramírez, F. A. (2014). Formando formadores. En A. Barrera \& P. Ramírez (Cords.), Inclusión con Responsabilidad, reformas educativas y profesionalización docente -Tomo III: Investigación Educativa y Políticas Públicas (pp. 67-72). Nayarit, Méjico: Universidad Autónoma de Nayarit.

Palomero, J. E. (2003). Breve historia de la formación psicopedagógica del profesorado universitario en España. Revista Interuniversitaria de Formación del Profesorado, 17(2), 21-41.

Paricio, J. (2010). Un modelo de guía docente desde los resultados de aprendizaje y su evaluación. ICE de la Universidad de Zaragoza. Recuperado de http://www.unizar.es/ice/ images/stories/calidad/Modelo\%20gu\%C3\%ADa\%20docente.pdf.

Perales, M. J., Jornet, J. M. \& González, J. (2014). Tendencias en las políticas de formación y evaluación del profesorado en la educación superior en España. Revista Iberoamericana de Evaluación Educativa, 7(2e), 53-64.

Pimienta, J.H. (2011). Secuencias didácticas: Aprendizaje y evaluación de competencias en educación superior. Bordón, 63(1), 77-92.

Postareff, L., \& Nevgi, A. (2015). Development paths of university teachers during a pedagogical development course. Educar, 51(1), 37-52. Recuperado de http://dx.doi.org/ $10.5565 / \mathrm{rev} / \mathrm{educar} .647$. 
Prieto, L. (2004). La alineación constructiva en el aprendizaje universitario. En J.C. Torre \& E. Gil (Eds.), Hacia una enseñanza centrada en el aprendizaje (pp. 111-142). Madrid: Edisofer.

Professional and Organizational Development Network in Higher Education. (2016). What is educational development? Recuperado de http://podnetwork.org/about-us/what-iseducational-development/.

Reyes, M. I. (2000). Perfil ideal del profesor: Una guía para detectar necesidades de formación. Recuperado de http://www.congresoretosyexpectativas.udg.mx/ Congreso\%203/ Mesa\%204/Mesa4_29.pdf.

Reyes, W., \& González, R. (2007). Aproximación de la fundamentación teórica de un modelo de formación docente constructivista. Omnia, 13(3), 131-154.

Rodríguez, M. (2003). John Henry Newman y su idea de la universidad. Cristianismo, Universidad y Cultura, 7, 1-9.

Rodríguez, R. M. (2008). Reaprender a enseñar: Una experiencia de la formación para la mejora continua de la docencia universitaria. Revista Interuniversitaria de Formación del Profesorado, 17(2), 79-94.

Rué, J. (2009). El aprendizaje autónomo en educación superior. Madrid: Narcea.

Rué, J., \& de Corral, I. (2007). Significados de la "formación docente" en las universidades españolas en el marco del EEES. Revista de Docencia Universitaria, 2, 1-23. Recuperado de http://www.redu.m.es/Red_U/2.

Ruiz, J. M. (2010). Evaluación del diseño de una asignatura por competencias, dentro del EEES, en la carrera de Pedagogía: Estudio de un caso real. Revista de Educación, 351, $435-460$.

Salas, R. S. (2000). La calidad en el desarrollo profesional: Avances y desafíos. Revista Cubana de Educación Médica Superior, 14(2), 136-147.

Sales, A. (2006). La formación inicial del profesorado ante la diversidad: Una propuesta metodológica para el nuevo Espacio Europeo de Educación Superior. Revista Interuniversitaria de Formación del Profesorado, 20(3), 201-217.

Sánchez, M., \& Mayor, C. (2006). Los jóvenes profesores universitarios y su formación pedagógica: Claves y controversias. Revista de Educación, 339, 923-946.

Silverman, D. (2003). Analyzing talk and text. En N. K. Denzin \& Y. S. Lincoln (Eds.), Collencting and interpreting qualitative materials (2a. ed.) (pp. 340-362). Thousand Oaks, CA: SAGE Publications.

Sorcinelli, M. D., Austin, A. E., Eddy, P. L., \& Beach, A. L. (2006). Creating the future of faculty development. Bolton, MA: Anker Publishing Company.

Stankeviciene, J. (2007). Assessment of teaching quality: Survey of university graduates. En European Conference on Educational Research (pp. 1-9). Ghent, Bélgica: University of Ghent. 
Stes, A., \& Van Petegem, P. (2015). Impacto de la formación del profesorado universitario: aspectos metodológicos y propuesta para futuras investigaciones. Educar, 51(1), 13-36. Recuperado de http://dx.doi.org/10.5565/rev/educar.642.

Torra, I., Màrquez, M. D., Pagès, T., Solà i Ysuar, P., García, R., Molina, F., González, A. P. et al. (2013). Retos institucionales de la formación del profesorado universitario. Revista de Docencia Universitaria 11(1), pp. 285-309.

Trillo, F. (2005). Competencias docentes y evaluación auténtica: ¿Falla el protagonista? Revista Perspectiva Educacional, 45, 85-103.

Taylor, S. J., \& Bogdan, R. (1998). Introduction to qualitative research methods: a guidebook and resource (3a. ed.). Hoboken, NJ: John Wiley \& Sons.

Urosa, B. (2004). Orientaciones para la selección y evaluación de actividades de aprendizaje dirigidas al desarrollo de competencias profesionales en el Espacio Europeo de Educación Superior. En J. C. Torre \& E. Gil (Eds.), Hacia una enseñanza centrada en el aprendizaje (pp. 191-217). Madrid: Edisofer.

Vázquez, G., Colom, A. J., \& Sarramona, J. (1998). Evaluación de la universidad: Criterios de calidad. Teoría y Educación, 10, 55-94.

Vera Vélez, L. (2002). Medición, "assessment" y evaluación del aprendizaje. San Juan, PR: Publicaciones Puertorriqueñas.

Verdejo, A. L., \& Medina, M. del R. (2009). Evaluación del aprendizaje estudiantil (5a. ed.). San Juan, PR: ExPERTS Consultants.

Vizcarro, C. (2009). Las experiencias y el proceso de innovación en el contexto académico. En Vizcarro, C. (Ed.), Buenas prácticas en docencia y política universitarias (pp. 1529). Madrid: Edisofer.

Villarroel, C. A. (1995). La enseñanza universitaria: de la transmisión del saber a la construcción del conocimiento. Educación Superior y Sociedad, 6(1), 103-122.

Yot, C., \& Mayor, C. (2012). Nuevas tendencias en el proceso de formación y mentoría de Profesores universitarios noveles en su primer año de docencia. Olhar de professor, Ponta Grossa, 15(2), 297-314. doi: 10.5212/OlharProfr.v.15i2.0007

Zabalza, M. A. (Ed.). (2005). Competencias docentes. En La universidad y la docencia en el mundo de hoy (pp. 87-125). Cali, Colombia: Pontificia Universidad de Cali.

Zabalza, M. A. (2007). La enseñanza universitaria: El escenario y sus protagonistas (3a. ed). Madrid: Narcea Ediciones.

Zabalza, M. A. (2009). Competencias docentes del profesorado universitario (2a. ed). Madrid: Narcea Ediciones.

Zabalza, M. A., \& Zabalza, A. (2010). Planificación de la docencia en la universidad: Elaboración de las guías docentes de las materias. Madrid: Narcea Ediciones. 